\title{
A Computational Fluid-Dynamics assessment of the improved performance of aerodynamic rain gauges
}

\author{
Matteo Colli $^{1,2}$, Michael Pollock ${ }^{3,4}$, Mattia Stagnaro ${ }^{1,2}$, Luca G. Lanza ${ }^{1,2}$, Mark Dutton ${ }^{4}$ and \\ Enda O'Connell ${ }^{3,4}$ \\ ${ }^{1}$ Department of Civil, Chemical and Environmental Engineering, University of Genova, Italy \\ ${ }^{2}$ WMO/CIMO Lead Centre "B.Castelli" on Precipitation Intensity, Italy \\ ${ }^{3}$ Newcastle University, Newcastle-Upon-Tyne, UK \\ ${ }^{4}$ Environmental Measurements Ltd, Newcastle-Upon-Tyne, UK
}

\section{Key Points:}

- Atmospheric precipitation measurements

- Wind-induced errors of precipitation gauges

- Computational Fluid Dynamics modelling 


\begin{abstract}
All rain gauges mounted above the ground surface present an obstruction to the prevailing wind. The airflow surrounding the gauge is deformed by this blockage. There is an acceleration of wind above the orifice of a gauge, which deflects raindrops and snowflakes away from the orifice, to land 'downstream' of the area represented by the gauge. This reduces the collection efficiency and causes what is commonly referred to as 'wind-induced undercatch'. The method of mounting a gauge with the collector at or below the level of the ground is often not practicable, therefore it is important to mitigate the effect of the wind-induced undercatch by other means where possible. The physical shape of a gauge has a significant impact on its collection efficiency. In this study, we show that appropriate 'aerodynamic' shapes are able to reduce the deformation of the airflow, which can reduce undercatch. We employed computational fluid-dynamic simulations to evaluate the time-averaged airflow realized around 'aerodynamic' rain gauges when impacted by wind. Terms of comparison are provided by the results obtained for two standard 'conventional' rain gauge shapes. The simulations have been run for different wind speeds and are based on a time-averaged Reynolds Averaged Navier-Stokes model. The shape of the aerodynamic gauges is shown to have a positive impact on the time-averaged airflow patterns observed around the orifice compared to the conventional shapes. Furthermore, the turbulent air velocity fields for the aerodynamic shapes present 'recirculating' structures, which may improve the particle-catching capabilities of the gauge collector.
\end{abstract}

\title{
1 Introduction
}

Obtaining accurate measurements of precipitation is a complicated undertaking. For such a fundamental and underpinning hydrological process, there exists an alarming amount of uncertainty, which is often unappreciated by the scientific community. Rain gauges are widely considered the most accurate method of quantifying precipitation at a point in space and time. Globallly, rain gauge networks deliver products of varying quality, which are used widely in applications such as water resources quantification, flood forecasting and warning, and numerical weather prediction.

Inherent systematic errors (biases) are introduced via two means, broadly defined as 'instrumental' and 'environmental' errors; these are also considered as 'counting' and 'catching' errors, respectively (Table 1). The former are related to the ability of a rain gauge to 'sense' and correctly quantify the precipitation particles as they pass through the instrument. Environmental or 'catching' errors are determined by the ability of a rain gauge aperture to collect a quantity of precipitation which is characteristic of the area of ground it is intended to represent. In other words, this is the ability to represent the rate or quantity of precipitation which would have landed on the ground surface area covered by the rain gauge, if the rain gauge itself were not present. The counting errors of rain gauges are well documented in

Table 1. Summary of the sources of error in rainfall measurement for a tipping-bucket type automatic gauge

\section{COUNTING ERRORS}

\section{CATCHING ERRORS}

- Mechanical losses at different rainfall intensities

- Repeatability of tipping bucket mechanism

- Wind-induced errors due to the gauge shape

- Blockages of the mechanical components and mounting height

- Electronic, algorithm and logging errors

- Evaporation of the uncounted rainfall

- Drops splash in/out of the collector

- Wetting of the funnel and the tipping bucket surfaces

- Water adhesion to the funnel and tipping buckets surfaces

the laboratory and field intercomparisons of rainfall intensity gauges promoted by the World Meteorological Organization [Lanza and Stagi, 2009; Lanza and Vuerich, 2009]. High- 
lighted in bold in Table 1 are wind-induced errors that are considered in this study, which contribute to the overall uncertainty characterizing precipitation measurements. Mounting a gauge at or below the level of the ground is widely accepted to negate this effect for rainfall. However, it is often not practicable to mount gauges below ground. Therefore, it is important to mitigate the effect of the wind-induced undercatch by other means where possible.

The physical shape of a gauge has a significant impact on its collection efficiency. In this study, we show that appropriate 'aerodynamic' shapes are able to reduce the deformation of the airflow, which can reduce undercatch. Two 'conventional' rain gauge shapes were selected on the basis of their use in operational networks. The straight-sided cylindrical gauge, the Casella, is used globally and in particular by the Environment Agency's (EA) network in England. This shape was selected due to its similarity to shapes of the majority of other TBRs, although the refinement of their edges can slightly differ.

The other non-aerodynamic (weighing) rain gauge selected is the OTT Pluvio ${ }^{2}$. This gauge was also chosen based on its use in operational networks. For example, it is used by the EA and the Scottish Environment Protection Agency (SEPA) in particular at remote locations, which are often in highly exposed environments [Grust and Stewart, 2012; Active, 2017]. The Pluvio ${ }^{2}$ is similar in shape to most other typical weighing rain gauges. Therefore, the two conventional shapes chosen and described here represent good examples of a 'typical' TBR shape and a 'typical' weighing gauge shape, respectively.

The other two models were selected specifically for their aerodynamic shape (Figure 1). The EML ARG100 rain gauge was designed in the early 1980s at the then Institute of Hydrology, Wallingford, UK (now Centre for Ecology and Hydrology). The gauge profile was created to reduce interference to the surrounding wind flow. Considerable work was subsequently undertaken in the early 2000s to optimise the shape through extensive empirical work based on field trials of various iterations of the gauge shape, documented in Strangeways [2004]. The final optimised shape became the basis of a commercial product, which is now the EML SBS gauge. This final gauge profile represents a trade-off between minimising the wind impact and reducing out-splash [Strangeways, 2004]. The EML SBS500 is now used operationally by the UK Met Office and the Scottish Environment Protection Agency in their networks of tipping bucket rain gauges. The positive effects of using 'aerodynamic'

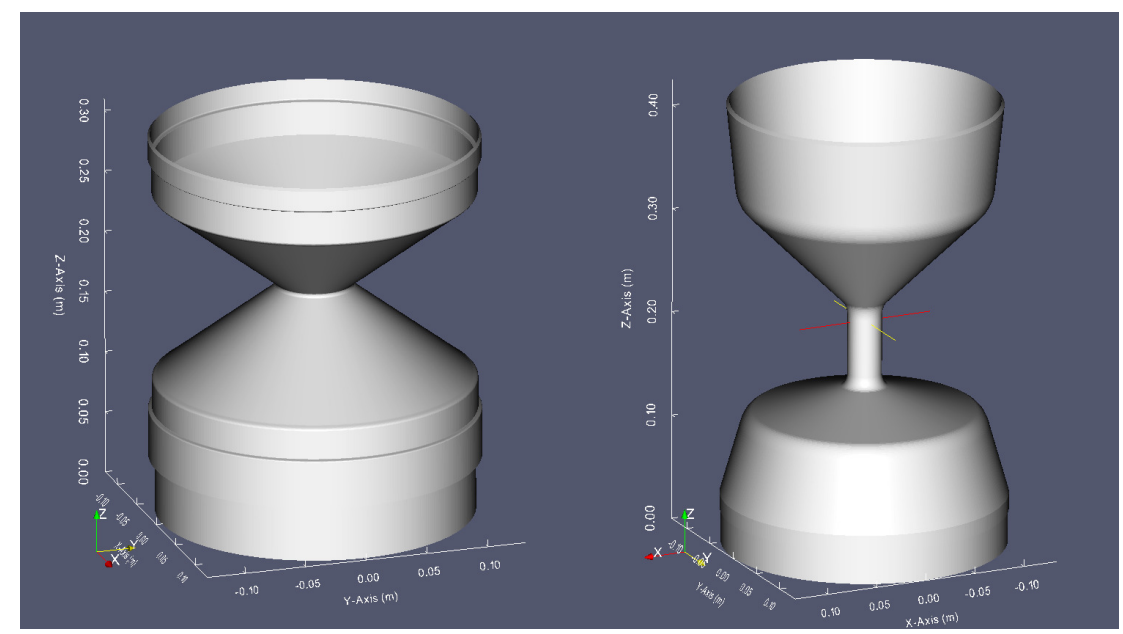

Figure 1. 3D models of the EML ARG100 (left panel) and the EML SBS500 (right panel) tipping bucket rain gauges. The orifice diameters of the two gauges are equal to $254 \mathrm{~mm}$; their heights are $310 \mathrm{~mm}$ and 425 $\mathrm{mm}$. The models are not to scale.

shapes of the above kind are evaluated by studying the deformation of the airflow around both conventional and aerodynamic gauges with a Computational Fluid Dynamics (CFD) nu- 


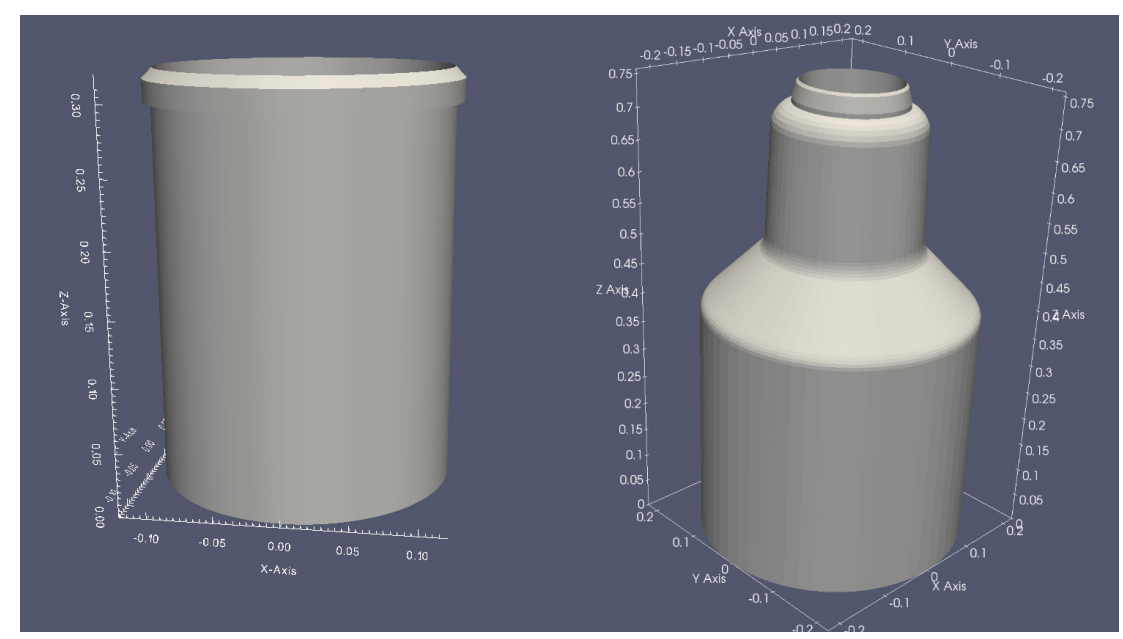

Figure 2. 3D models of the Casella (left panel) and the OTT Pluvio ${ }^{2}$ (right panel) tipping bucket rain gauges. The orifice diameters of the two gauges are $228 \mathrm{~mm}$ and $160 \mathrm{~mm}$; their heights are $320 \mathrm{~mm}$ and 757 $\mathrm{mm}$. The models are not to scale.

merical model. Firstly, we review previous work on the assessment of rain gauge undercatch due to wind effects, including previous CFD simulation experiments. The CFD model set-up is then described, followed by the presentation of the results in graphical form, together with some numerical measures of aerodynamic performance. 


\section{Examining the evidence for wind-induced undercatch}

The wind-induced measurement error is considered the most significant cause of environmental or 'catching' bias [Sevruk and Hamon, 1984; Goodison et al., 1998; Yang et al., 1999; Strangeways, 2004; Benning and Yang, 2005; Sieck et al., 2007; Mekonnen et al., 2015], and quantification of the inaccuracies associated with wind-induced measurement errors is essential. Without this information, all modelling and subsequent decision making is based on flawed knowledge, particularly when estimating precipitation in upland areas for storms characterized by high wind speeds.

All rain gauges mounted above the ground surface present an obstruction to the prevailing wind. The airflow surrounding the gauge is deformed by this blockage. Invariably, there is an acceleration of wind above the orifice of a gauge, which deflects raindrops and snowflakes away from the orifice, to land 'downstream' of the area represented by the gauge. This reduces the collection efficiency and causes what is commonly referred to as 'windinduced undercatch'.

The trajectories of precipitation particles become distorted in wind through the displacement and acceleration of wind flow over the top of the gauge [Warnick, 1956; Sevruk and Hamon, 1984; Folland, 1988; Goodison et al., 1998]. The extent of reduction (undercatch) due to the wind effect is a function of the wind speed at gauge orifice (and inside the gauge), precipitation type and particle falling velocities (drop size and distribution), rainfall intensity and the aerodynamic properties of a particular type of gauge. Furthermore, these variables are contingent upon the local climatology, so the wind-induced undercatch is site and season dependent; temperature therefore also can have an impact [Wolff et al., 2014].

Recent studies concentrate on the implications of wind bias correction for solid precipitation. Chubb et al. [2015] report that the observed precipitation amount in the Snowy Mountains, Australia, would in their worst-case scenario need to be increased by $52 \%$ to match what would have been recorded if appropriate shielding was available. Average seasonal undercatch was reported as being between $6 \%$ and $15 \%$ Chubb et al. [2015]. It is clear here and from other studies that the full specqtrum of wind-induced undercatch cannot be fully appreciated when it is averaged to this extent.

Current methods of precipitation interpolation simply do not cater for the level of uncertainty prevalent in all precipitation observations. In Canada, another recent study reports that bias corrections increased monthly precipitation by up to $163 \%$ at windy sites with short vegetation [Pan et al., 2016]. However, increases at sites shielded by forest were only $13 \%$.

Solid precipitation underestimation is not unique in its worthiness of great concern. Rainfall is also highly susceptible to wind-induced undercatch to a significant extent. Regions like the UK, which are prone to large coincident rainfall and wind events, such as the devastating Storm Desmond in December 2015, suffer greatly from this phenomenon. The extent to which this is so has not yet been fully quantified because of its highly dynamic nature. Archer et al. [2007] reports of a storm in the upper Tyne catchment in the UK where upland wind speeds exceeded $40 \mathrm{~ms}^{-1}$, resulting in the estimated sub-catchment precipitation being less than the measured runoff. Such underestimation can have important implications for the design of flood defences and the performance of real-time flood forecasting systems as well.

All historical precipitation measurements are therefore systematically deficient. The extent of this undercatch is unknown and constantly varying, due to the complexity of the inter-relationship between the set of dependent variables outlined above. There are several sources of uncertainty in the measurement of precipitation. The only widely accepted method of accurately measuring rainfall is by using a WMO reference pit gauge [Sevruk and Hamon, 1984; Lanza and Vuerich, 2009]. However, this is impractical for other than a limited number of research sites.

Despite the problem being identified as early as Heberden [1769], it has not been decisively dealt with. In the past, this may be due to a not sufficient capability of measuring precipitation at the temporal resolution required to describe the highly time-dependent physical process governing wind-induced error. This would be a pervasive problem when measuring using manual rain gauges. In addition, a lack of understanding of the physical basis of un- 
dercatch inhibited the development of methods of mitigating it. Attempts have been made to carry out some rainfall measurements correction based on existing data and empirical procedures [Sevruk, 1982], but the physical nature of this complex mathematical function has not been described adequately due to limitations in field data collection. Such methods are often restricted by a lack of relevant information, in space and in time. They may also be limited to a localised geographical location and for a particular dataset.

The quantification of wind-induced undercatch is commonly performed by comparing amounts measured by manual and automatic gauges with different shapes, mounting heights and wind shielding systems [Sevruk and Hamon, 1984; Goodison et al., 1998; Yang et al., 1999; Strangeways, 2004]. According to the CIMO Guide to Meteorological Instruments and Methods of Observations [WMO, 2012], the main feature of reference gauge design is to minimize or control the effect of wind on the catch, which is the most serious environmental factor for gauges at low intensity rates. This is achieved by installing the instruments within a reference pit [Sevruk and Hamon, 1984] realized according to the specifications provided by the European Standard 13798 [EN, 2002]. Such methods of investigation are therefore field based empirical investigations using real data captured in the environment.

A detailed study by Warnick [1956] examined the effect of the gauge orifice on the surrounding airflow, based on a wind tunnel experiment of the Sacramento and Radio-Reporting gauges [Warnick, 1956]. This laboratory investigation provided the first evidence of the sensitivity of airflow velocity and turbulence intensity close to the collecting orifices of different gauge shapes. Time-averaged CFD simulations of cylindrical and flat champagne glassshaped gauges were performed by Folland [1988] based on a Reynolds Averaged NavierStokes (RANS) $k-\epsilon$ model; the results of this work were corroborated by Sevruk et al. [1991]. These studies were among the first to apply CFD modelling methods to the windinduced rainfall undercatch problem. CFD has the potential to provide a mathematically robust method of assessing the effect of the wind on a rain gauge, and thus provide a level of understanding which could lead to the development of a physically-based correction algorithm, augmented by empirical evidence from high resolution field data. However, prior to the development of a robust correction algorithm, CFD simulations are a useful tool to evaluate what the optimal shapes for measuring precipitation are. Detailed estimates of the rainfall undercatch under different horizontal wind speeds were derived in Nešpor [1998] by coupling CFD airflows with a Lagrangian tracking model of the liquid particles. This study showed a significant influence of the rainfall intensity on the measurement undercatch for three different cylindrically-shaped gauges characterized by different orifices.

Constantinescu et al. [2006] describe the highly turbulent behaviour of the airflow observed around two MetOne gauges, characterized by a cylindrical shape, when a CFD analysis is performed based on Large Eddy Simulations (LES). The authors highlighted the importance of accounting for turbulence when coupling the CFD results with particle tracking models.

Further CFD simulations investigated the role of the precipitation particle crystal types and the particle size distribution for solid precipitation measurements made by a 'chimney'shaped Geonor T200B gauge with a single Alter shielded [Thériault et al., 2012]. Colli et al. [2016a,b] extended this CFD study to characterize the effect of the turbulent airflows generated by the single Alter wind-shield, and compared the results of RANS and LES approaches. More sophisticated modelling of the snow crystal hydrodynamics has been shown to increase the agreement between field observations and simulation estimates of the windinduced undercatch [Colli et al., 2015].

The above studies focused on simulating airflows around conventional cylindrical rain gauge shapes, or 'chimney' type rain gauge shapes where the diameter is reduced towards the top of the gauge. The present study provides a sound quantitative assessment of the turbulent air velocity fields realized by adopting aerodynamic rain gauge shapes, and assesses the possible implications for reducing undercatch with respect to conventional (or non-aerodynamic) shapes. The research focuses on two aerodynamic rain gauges; the ARG100 and the SBS500 which owe their designs to research carried out by Folland [1988] and Strangeways [2004], respectively. 
Table 2. Number of surface triangles adopted to model the rain gauges

\begin{tabular}{r|cc}
\hline Gauge & Number of surface triangles & Number of vertices \\
\hline Casella & 5760 & 2882 \\
OTT Pluvio & 5760 & 2882 \\
EML ARG100 & 61920 & 30962 \\
EML SBS500 & 53280 & 26642 \\
\hline
\end{tabular}

\section{Method of investigation}

The objective of this research is addressed by means of the following steps. Firstly, the simulation set-up activities are performed by modelling the gauge geometries and the spatial discretization of the environmental domain. Numerical schemes are chosen for the terms that appear in the CFD model being employed (derivatives, gradients, Laplacians and interpolations) and the simulation parameters are set. The time-averaged airflows for the four selected rain gauge shapes are then evaluated by means of a two-equation $k-\omega$ Shear Stress Tensor (SST) RANS model in a parallel computation framework. The open-source numerical solver OpenFOAM is used to perform the simulations. Finally, simulation results are processed to compute objective measures of comparison, and to provide graphical representations.

\subsection{Modelling gauge geometries and spatial discretization}

The first step of the investigation was the three-dimensional modelling of the rain gauge surfaces. The 3D models are composed of triangular two-dimensional elements; the number of triangles representing the rain gauge surfaces determines the quality of the $3 \mathrm{D}$ model. Table 2 reports the number of elements adopted for each 3D modelled gauge, prior to carrying out the CFD simulations. Compared to the traditional Casella gauge and the OTT Pluvio $^{2}$, the aerodynamic gauges required a greater number of elements due to their complex geometry. Figures 1 and 2 provide a three-dimensional view of the aerodynamic and traditional gauges respectively. Spatial discretization is the process by which a spatial computational domain, and the grid, or 'mesh' within it, is defined. For this study, the domain consists of a $3 m \times 3 m \times 9 m$ rectangular 'environmental box' with the geometries of the rain gauges located $3 \mathrm{~m}$ from the inlet boundary. The gauge geometries have been constructed to represent a 'true' 1:1 scale. Each gauge is placed on the 'floor' of the computational domain, therefore the top of a gauge's collecting orifice represents the height of each gauge. The three coordinates are orientated such that the $z$ axis refers to the vertical direction, the $x$ axis to the stream-wise and $y$ to the cross-wise direction (Figure 3 ). The origin of the axes lies at the center of the gauge collector in order to exploit the axial symmetry of the gauges.

The three-dimensional spatial domain was discretized using unstructured hybrid hexahedral/prismatic finite volume meshes, specifically tailored for each gauge geometry. Structured hexahedral meshes are commonly preferred due to their improved accuracy in solving viscous flows, and for the computational optimization they provide. However, hybrid unstructured meshes were chosen because of the necessity to employ an adaptive discretization method for these gauge geometries, while maintaining a good geometrical quality of the local cells adjacent to the wall boundary zones [Jasak, 1996]. The prismatic elements are well suited for binding the two-dimensional triangular elements, which lie on the modelled geometries. These are accompanied by staggered layers of cells that refine the regions affected by high gradients in the transport equations.

The quality of the meshes used in this section of the numerical activity have been verified by using standard parameters proposed by [Jasak, 1996], and detailed in the following. The mesh 'orthogonality' is defined as the angular deviation of the vector normal to the connecting face from the vector connecting the two cell centers; it adds numerical diffusion to the solution, damping the gradients of the flow fields. The 'skewness' is the deviation of the 


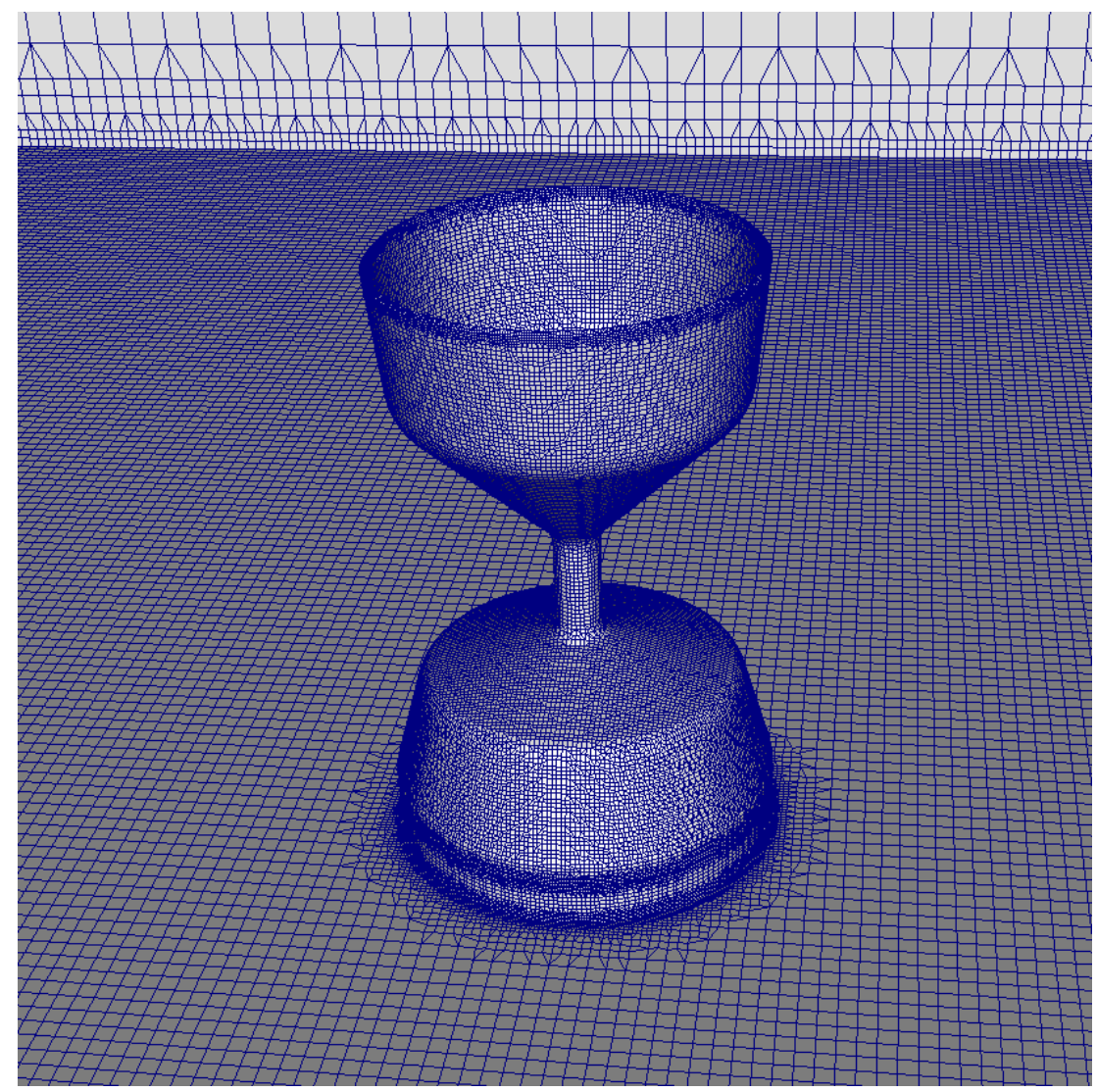

Figure 3. The EML SBS500 viewed within the computational domain from different perspectives.

Table 3. Geometric characteristics and quality factors (max cells skewness, non-orthogonality and aspect ratio) of different three-dimensional grids adopted to conduct the RANS simulations

\begin{tabular}{r|cc|ccc}
\hline Model & \multicolumn{2}{|c}{ N. elements $\left(10^{3}\right)$} & \multicolumn{3}{c}{ Max cells } \\
& hexa & prisms & skew. & non-ortho. & aspect ratio \\
\hline Casella & $\approx 800$ & 16.7 & 2.49 & 54.8 & 4.0 \\
OTT Pluvio $^{2}$ & $\approx 2000$ & 10.4 & 2.9 & 54.0 & 4.1 \\
EML ARG100 & $\approx 1000$ & 33.4 & 4.3 & 58.5 & 5.6 \\
EML SBS500 & $\approx 800$ & 9.6 & 3.2 & 50.0 & 4.2 \\
\hline
\end{tabular}

vector connecting any two cells from the face center and it also adds numerical diffusion to the solution. The mesh 'aspect ratio' (AR) is the ratio between the longest side and the shortest side of the cells. Large aspect ratios are acceptable only if the flow gradients in the directions of the longest sides are small. The characteristics and the values of the quality parameters associated with the different spatial grids realized in this activity are detailed in Table 3.

Figures 3, 4 and 5 provide examples of the finite volume spatial discretization adopted to carry out the CFD simulations. Figure 3 depicts the modelled geometric lattice of the EML SBS500 gauge. Figures 4 and 5 refer to the EML ARG100 meshing. This 3D geometric framework has been created for all gauges.

The adoption of the wall unit $y+$ guides the selection of an appropriate grid spacing in the regions close to the surfaces of the computational domain [Ariff et al., 2009]; $y^{+}$is 


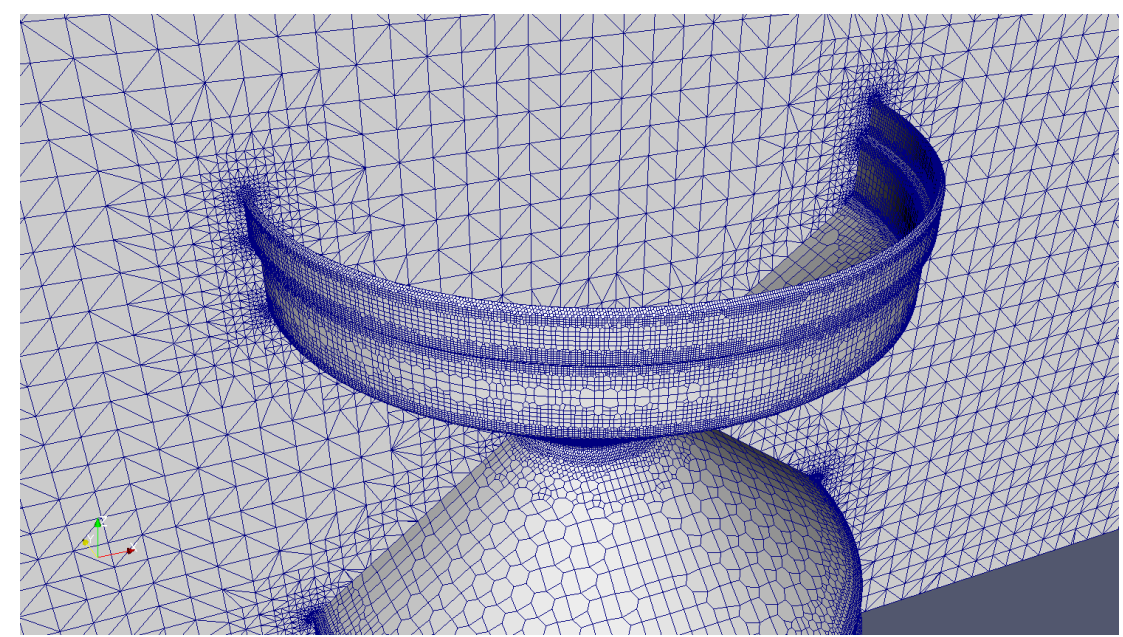

Figure 4. A stream-wise vertical section passing through the center of the EML ARG100. There is a high level of grid refinement close to the rain gauge collecting orifice in this depiction of the spatial discretization, because these are the positions of greatest interest.

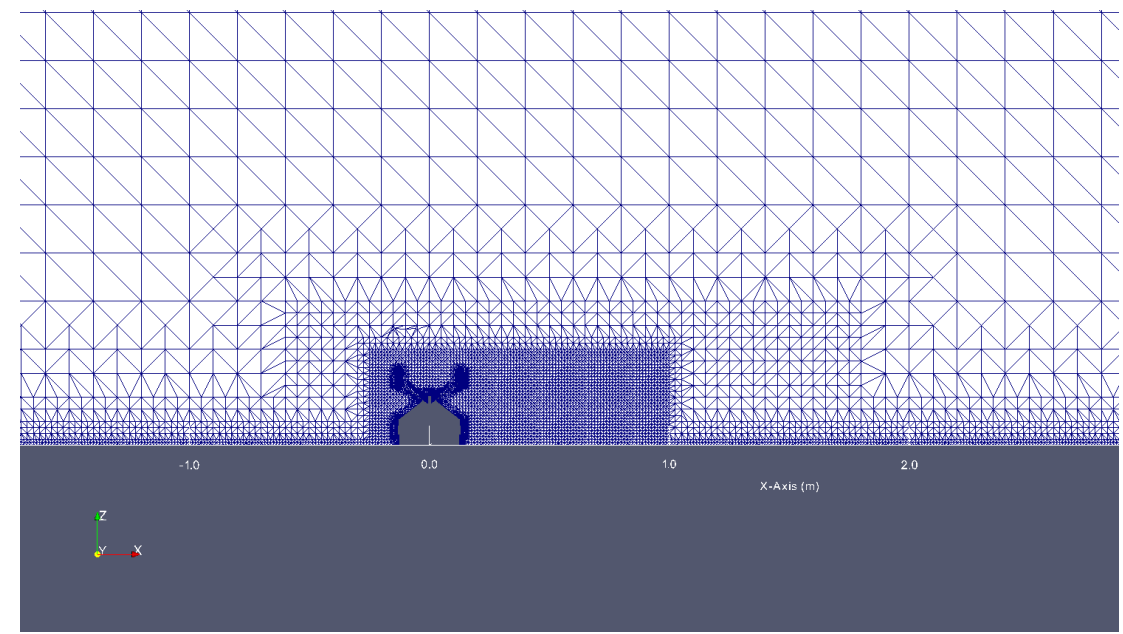

Figure 5. Stream-wise vertical section of the finite volumes spatial discretization of the EML ARG100 computational domain. Grades of refinement have been adopted at different proximities to the gauge. Areas of greatest refinement are closest to the gauge.

defined as:

$$
y^{+}=y u_{\tau} v^{-1}
$$

where $y(\mathrm{~m})$ is the distance to the wall, $u_{\tau}(\mathrm{ms}-1)$ is the friction velocity and $\left(\mathrm{m}^{2} \mathrm{~s}^{-1}\right)$ is the kinematic viscosity of the carrying fluid (air). The problem with such boundary layer regions is that the viscous stresses dominate the turbulent fluctuations, so high gradients of velocity are present.

The airflow patterns are solved by modelling the boundary layer regions of the flow with specific wall functions. This is reasonable since the problem of the wind driven turbulence is governed by the free flow regions and the wall function method noticeably reduces the computational requirement of the simulation.

There is not a unique indication about how large the space between the location of the first cell node and the wall surfaces should be. However, when a wall function is being used, 
Table 4. Values of the non-dimensional wall coordinate (wall unit) $y^{+}$calculated at the level of the first layer of cells surrounding the tested gauges. The results are obtained from the RANS dataset computed with $U_{w}=2 m s^{-1}$.

\begin{tabular}{c|c|ccc}
\hline Model & Gauge & min. $y+$ & max y+ & avg $y+$ \\
\hline RANS $\left(U_{w}=2 m / s\right)-$ & Casella & 0.001 & 22.370 & 3.001 \\
- & OTT Pluvio $^{2}$ & 0.007 & 42.688 & 3.225 \\
- & EML ARG100 $^{-}$ & 0.002 & 30.514 & 1.551 \\
- & EML SBS500 & 0.037 & 25.288 & 3.544 \\
\hline
\end{tabular}

one has to locate at least the first node within the boundary layer $\left(y^{+}<100\right)$ in order to allow the model to correctly interpolate the profile of the modeled variable [Launder and Spalding, 1974]. It is considered good practice to verify, in a post-process phase, the actual $y^{+}$values realized around the object surfaces. This is because the values of $u_{\tau}$ in the standard $y^{+}$calculation are not known "a priori". Subsequently, the mesh sizing should be adjusted in order to dimension the first cell layer with an appropriate height. Table 4 reports the calculation of the minimum, maximum and averaged $y^{+}$values on the first cell nodes wrapping the gauge surface from the RANS dataset, where $U_{w}=2 \mathrm{~ms}^{-1}$. In all proposed gauges, the first layer was sized so as to have the corresponding wall unit value comprised within the boundary layer and hence the wall function correctly applied. 


\subsection{The fluid-dynamic model}

There is no universally applicable approach for physically calculating the complexities of fluids when they exhibit non-laminar flow (turbulence); each modelling scheme adopted must balance simplifications/assumptions and representativeness of the solution. However, measures can be taken to check and verify that the most appropriate model and modelling technique are selected for any given application. The time-independent simulations performed in this study are based on the two-equation RANS model [Menter, 1993] that is widely used in CFD practice for simulating a number of turbulent flows with a finite volume discretization. It is convenient to specify the fluctuating velocity $u\left(\mathrm{~ms}^{-1}\right)$ and pressure per unit density $p\left(m^{2} s^{-2}\right)$, in terms of the spatial coordinates $x$ and the time $t$, as follows:

$$
\begin{aligned}
& \mathbf{u}(\mathbf{x}, t)=\hat{\mathbf{u}}(\mathbf{x})+\mathbf{u}^{\prime}(\mathbf{x}, t) \\
& p(\mathbf{x}, t)=\hat{p}(\mathbf{x})+p^{\prime}(\mathbf{x}, t)
\end{aligned}
$$

where the hat symbol is used to indicate arithmetic means and the apostrophe refers to a realization of the random variable. The Navier-Stokes system of equations can be written under the assumption of isothermal flow, constant viscosity and a Reynolds-averaging of the velocity vector, obtaining the Reynolds-Averaged Navier Stokes (RANS) equations in the form:

$$
\begin{aligned}
\nabla \cdot(\hat{\mathbf{u}}) & =0 \\
\frac{\partial \hat{\mathbf{u}}}{\partial t}+\nabla \cdot(\hat{\mathbf{u}} \hat{\mathbf{u}}) & =\frac{-\nabla \hat{p}}{\rho}+\nu \nabla^{2} \hat{\mathbf{u}}-\frac{1}{\rho} \nabla \cdot \tau^{R}
\end{aligned}
$$

where $\rho$ is density, $v$ the kinematic viscosity and $\tau^{R}$ is the Reynolds-stress tensor defined as:

$$
\tau^{R}=-\rho\left(\overline{\mathbf{u}^{\prime} \mathbf{u}^{\prime}}\right)
$$

The turbulent kinetic energy $k\left(m^{2} s^{-2}\right)$ is the kinetic energy per unit mass of the turbulent fluctuations $u^{\prime}$ in a turbulent flow:

$$
k=\frac{1}{2}\left(<u^{\prime 2}>+<v^{\prime 2}>+<w^{\prime 2}>\right)
$$

The turbulent dissipation $\epsilon\left(\mathrm{m}^{2} \mathrm{~s}^{-2}\right)$ is the rate at which $\mathrm{k}$ is converted into thermal internal energy per unit mass. For incompressible flows:

$$
\epsilon=v \overline{\frac{\partial u_{i}^{\prime}}{\partial x_{k}} \frac{\partial u_{i}^{\prime}}{\partial x_{k}}}
$$

The common formulations of the RANS model couple the governing equation of the turbulent kinetic energy with a second transport expression that satisfies a differential equation similar to $k$. This additional expression is generally formulated for either $\epsilon$ or $\omega\left(s^{-1}\right)$, the turbulence specific dissipation rate, depending on the specific problem and characterizes the $k-\epsilon$ and $k-\omega$ two-equation models. The turbulence specific dissipation rate is related to $\mathrm{k}$ by means of the kinematic eddy viscosity ${ }_{t}=k \omega^{-1}\left(m^{2} s^{-1}\right)$ as detailed by Wilcox [2006]. When solving free-stream flows with relatively small pressure gradient, the $k-\epsilon$ models provide reliable results [Bardina et al., 1997]. The accuracy of the solution is reduced for bounded flows with large adverse pressure gradients. Modern RANS solvers included on CFD toolkits such as OpenFOAM and ANSYS Fluent allow the user to apply a more advanced method that concentrates the main advantages of the $k-\omega$ and $k-\epsilon$ two-equation models and that is usually referred to as the Shear Stress Tensor (SST) $k-\omega$ model [Menter, 1993]. The use of a SST $k-\omega$ method in the inner parts of the boundary layer makes the model directly usable down to the wall through the viscous sub-layer. The SST formulation also switches to a $k-\epsilon$ behavior in the free-stream, and thereby avoids the common $k-\omega$ problem that the model is too sensitive to the inlet free-stream turbulence properties. 


\subsection{Fluid property assumptions}

The fluid air has been characterized as a Newtonian incompressible fluid with a kinematic viscosity $v_{a}=1.40 \cdot 10^{-5} \mathrm{~m}^{2} \mathrm{~s}^{-1}$ and a density $\rho_{a}=1.25 \mathrm{kgm}^{-3}$, at the environmental temperature $T_{a}=10^{\circ} \mathrm{C}$. The present work does not consider possible variations of the air density with temperature that occur in the real world. We assume this contribution as negligible with respect to other factors governing the airflow turbulence.

\subsection{Initial and boundary conditions}

With reference to the rectangular computational domain, the undisturbed wind speed $U_{w}\left(m s^{-1}\right)$ was imposed parallel to the longest side ( $x$ axis) which is $9 m$ long. The velocity profiles of the vertical ( $z$ axis) and cross-wise ( $y$ axis) directions were maintained uniform and constant in time. These conditions were imposed on the inlet face of the domain that is represented by the $y-z$ plane located at $x=-3.0 \mathrm{~m}$.

The airflow outlet is imposed on the opposite face with respect to the inlet ( $x=6.0$ $m$ ). The other three faces of the domain (excluding the ground surface) are assumed as slipcondition planes, i.e. the field values computed in the nodes adjacent to the boundary are modelled as symmetric to the outside nodes adjacent to the other side symmetry plane. Both the ground and rain gauge surfaces are assumed impermeable, and non-slip conditions are imposed.

The initial conditions defined at the internal nodes before running a RANS simulation are specified as:

Velocity: $v=\left(U_{w}, 0,0\right) m s^{-1}$ where $U_{w}\left(m s^{-1}\right)$ is the averaged uniform wind speed. The CFD simulations has been repeated by imposing $U_{w}=2,5,7,10$ and $18 \mathrm{~ms}^{-1}$.

Relative pressure: $p=0 \mathrm{~m}^{2} \mathrm{~s}^{-2}$ (where the pressure units are normalized with the air density).

Turbulent kinetic energy: estimated as $k=3 / 2\left(I U_{w}\right)^{2}$ calculated for an average wind speed $U_{w}$ and a turbulent intensity $I=0.20$ evaluated from field measurements [Pollock et al., 2015]. The 3-dimensional wind observations have been measured using a Gill WindMaster ultrasonic anemometer at a resolution of $20 \mathrm{~Hz}$. They were captured at a UK field site in the northeast of England at the orifice height of an SBS500 gauge, mounted directly on the ground.

Turbulent specific dissipation rate: $\omega=\rho_{a} k / \mu_{\tau}\left(s^{-1}\right)$ with $k$ evaluated by using the preceding equation and approximating the dynamic eddy viscosity $\mu_{\tau}\left(\mathrm{kgm}^{-1} \mathrm{~s}^{-1}\right)$ to the dynamic viscosity of the air $\mu\left(\mathrm{kgm}^{-1} \mathrm{~s}^{-1}\right)$. 


\section{Simulation results}

To investigate the impact of the airflow on precipitation particle trajectories, the principal areas of interest are around, within and above the gauge collector's area. Visualisation of this region is achieved by using two-dimensional contours, color plots and vertical profiles of the air velocity components and the turbulent kinetic energy in the vicinity of the gauge orifice. With the aim of improving the comparability between the panels of the fluid-dynamic variables, the spatial coordinates have been normalized with the gauge collector diameter $D$ $(x / D, y / D$ and $z / D)$ and the origin is located at the center of the collector.

\subsection{Vertical component of the air velocity}

Figures 6 and 7 are contour plots of the vertical component $U_{z}$ of the air velocity, observed on a horizontal plane located at the gauge collector level, for wind speeds of $U_{w}=10$ $m s^{-1}$ and $U_{w}=18 \mathrm{~ms}^{-1}$, respectively. The OTT and the Casella gauges are located in the top left and the top right positions, respectively. The EML ARG100 and the EML SBS500 are in the bottom left and the bottom right positions, respectively. All subsequent plots in this paper follow the same order. The same scale is used for the four gauges in each plot, so they are directly comparable. For descriptive purposes, the OTT and Casella gauges are grouped as the gauges with a 'conventional' shape; the ARG100 and the SBS500 are grouped as the 'aerodynamic' gauges.
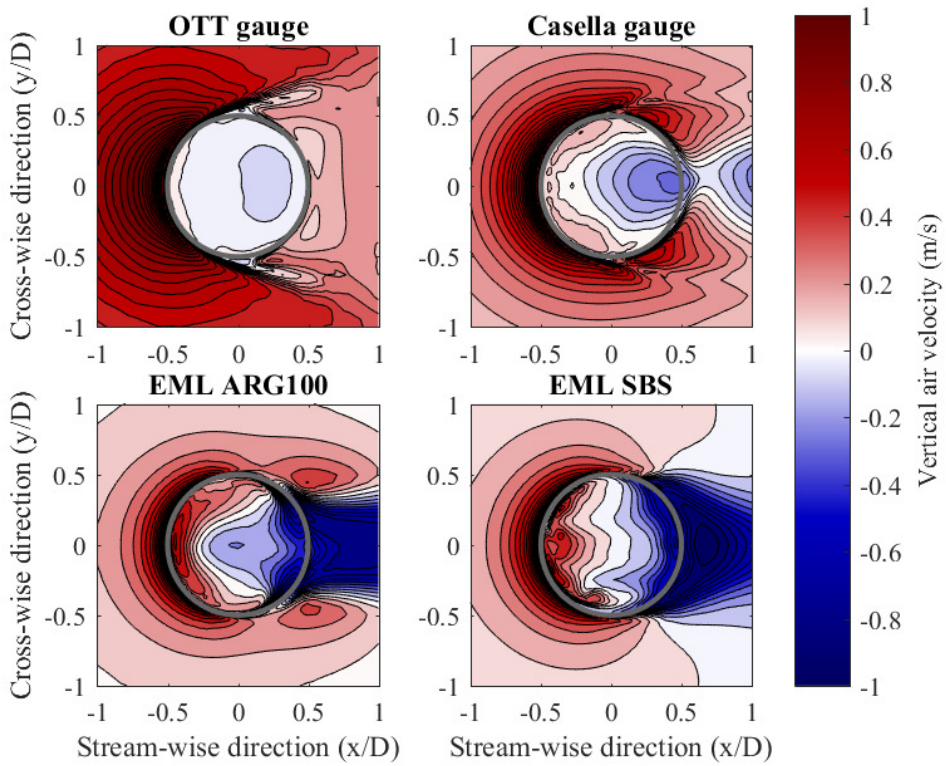

Figure 6. Horizontal contour plots showing the vertical component of airflow velocity $U_{z}\left(m s^{-1}\right)$ observed at the gauge collector level. The values have been computed by executing SST RANS $k \quad-\quad \omega$ simulations with a horizontal wind speed $U_{w}$ equal to $2 \mathrm{~ms}^{-1}$. The spatial coordinates are normalized with the collector diameter.

The OTT and the Casella gauges show distributed updrafts (red areas) around the collector with higher values upwind of the orifice rim. This evidence is also confirmed by the representations of $U_{z}$ on a vertical plane for all the simulated wind conditions and is detailed in Table 5 for the sample wind speed $U_{w}=10 \mathrm{~ms}^{-1}$. Table 5 shows non-dimensional values of the air velocity components normalized for the wind speed $U_{w}$ and turbulent kinetic energy $k$ normalized with $U_{w}^{2}$ observed in two different points located upstream and inside 

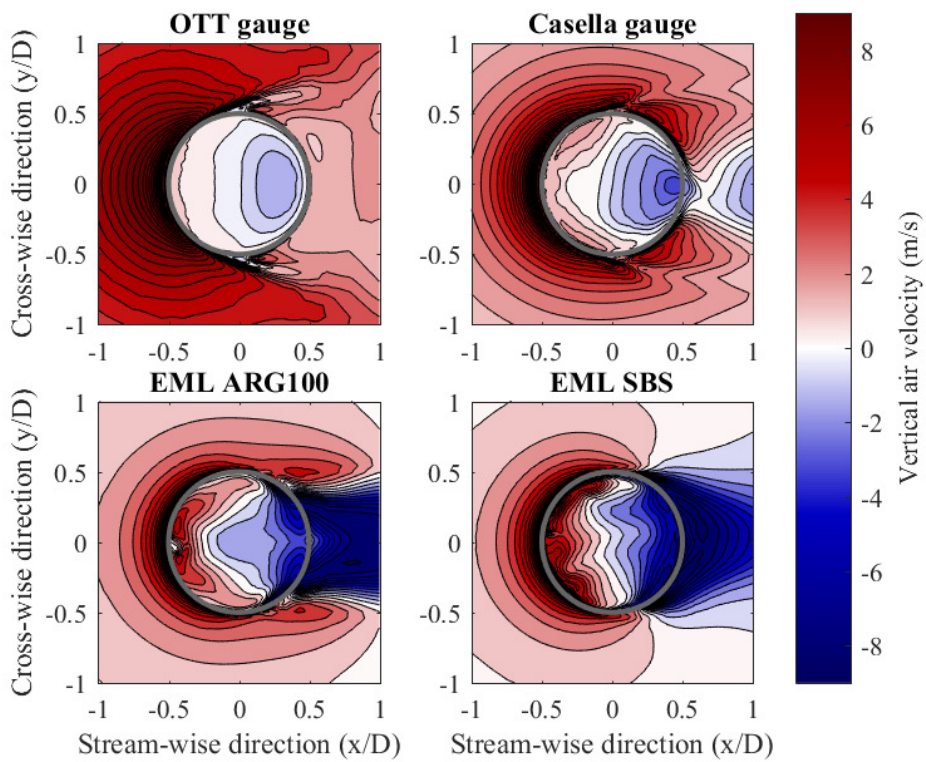

Figure 7. Horizontal contour plots showing the vertical component of airflow velocity $U_{z}\left(m s^{-1}\right)$ observed at the gauge collector level. The values have been computed by executing SST RANS $k-\omega$ simulations with a horizontal wind speed $U_{w}$ equal to $18 \mathrm{~ms}^{-1}$. The spatial coordinates are normalized with the collector diameter.

the orifice (respectively $x / D=-0.6$ and $x / D=0.40)$ in the symmetry plane $(y / D=0)$ at the gauge collector level, as highlighted in Figure 8. The values of $U_{z} / U_{w}$ measured outside the collector and just before the orifice $(x / D=-0.6)$ equal 0.71 for the OTT gauge and 0.55 for the Casella model. The two aerodynamic gauges show much lower values with minor differences between them $\left(U_{z} / U_{w}\right.$ equals 0.40 for the ARG100 gauge and 0.41 for the SBS500). The values of the non-dimensional magnitude of velocity $U / U_{w}$ computed at the same location reflect lower airflow velocity regimes in the case of the aerodynamic shapes.

Recent studies [Thériault et al., 2012; Colli et al., 2015, 2016a,b] showed that a similar positive vertical component of the airflow velocity tends to shift upward the trajectories of non-liquid precipitation particles, which is the principal cause of wind-induced undercatch. A similar behaviour is expected also for rainfall even if reduced by the heavier hydrodynamic classification of liquid particles [Colli, 2014]. Note that the region inside the aerodynamic collector between -0.5 and 0 in the streamwise direction $(x / D)$ is characterized by higher magnitudes of $U_{z}$ compared to the OTT and the Casella gauges. On the other hand, the downdraft (blue areas) occurring between 0 and 1 of the stream-wise direction $(x / D)$ close to the orifice is wider and stronger for the aerodynamic gauges than for conventional gauges. This relevant downdraft inside the aerodynamic gauge collectors is also highlighted by the vertical non-dimensional velocity values reported in Table 5 at the $x / D=0,4$ position. For a wind speed $U_{w}=10 \mathrm{~ms}^{-1}$,the SBS500 model show a stronger $U_{z} / U$ result equal to $-0,34$ in contrast with the OTT model which shows the minimum vertical velocity magnitude $\left(U_{z} / U=-0,04\right)$ among the tested gauges. The presence of a strong downdraft inside the gauge orifice may facilitate the convergence of the particle trajectories, thus increasing the collection efficiency [Colli et al., 2016b]. A Lagrangian particle-tracking model could help identify the role of these patterns on the collection performance of the gauge, which is not easily deducible a priori.

Figure 9 shows the magnitude of velocity $U_{m}$ represented on a stream-wise vertical plane for the different gauges. The white band displayed for all gauges represents the shear 


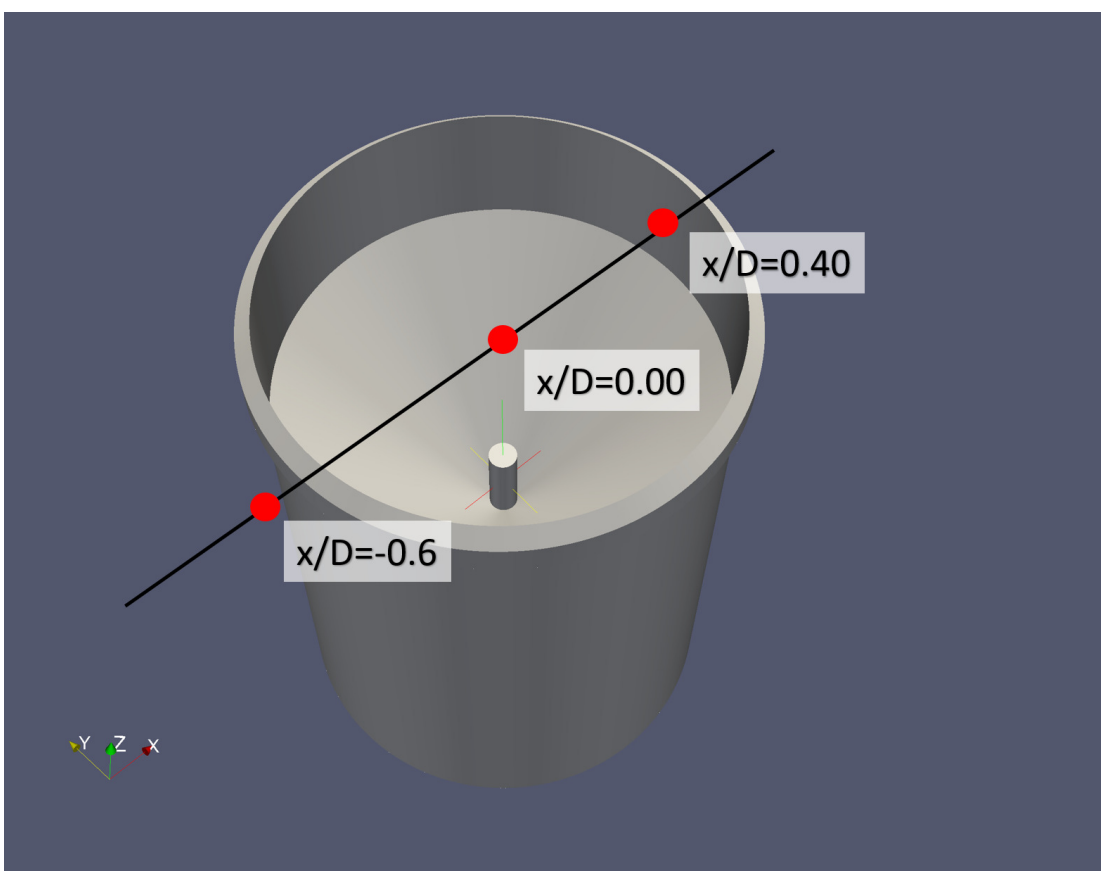

Figure 8. Stream-wise position of the virtual measurement probes located at the gauge orifice level.

Table 5. Non-dimensional values of the air velocity components $\left(U_{x} / U_{w}, U_{y} / U_{w}, U_{z} / U_{w}\right)$, magnitude of velocity $U / U_{w}$ and turbulent kinetic energy $k / U_{w}^{2}$ computed by the RANS $k \quad-\omega$ SST model at the gauge collector level $z / D=0$, and at $y / D=0$ for a wind speed $U_{w}=10 \mathrm{~ms}^{-1}$

\begin{tabular}{r|cccccc} 
& $x / D$ & $U_{x} / U_{w}$ & $U_{y} / U_{w}$ & $U_{z} / U_{w}$ & $U / U_{w}$ & $k / U_{w}^{2}$ \\
\hline ARG100 & $-0,60$ & 0,63 & 0,01 & 0,41 & 0,75 & $1,75 \mathrm{E}-07$ \\
SBS500 & $-0,60$ & 0,63 & 0,00 & 0,40 & 0,74 & $2,13 \mathrm{E}-07$ \\
OTT & $-0,60$ & 0,72 & 0,00 & 0,71 & 1,01 & $3,26 \mathrm{E}-05$ \\
CASELLA & $-0,60$ & 0,64 & 0,01 & 0,55 & 0,84 & $4,00 \mathrm{E}-07$ \\
\hline ARG100 & 0,40 & 0,16 & 0,00 & $-0,16$ & 0,22 & $8,20 \mathrm{E}-03$ \\
SBS500 & 0,40 & 0,27 & 0,01 & $-0,34$ & 0,43 & $2,89 \mathrm{E}-03$ \\
OTT & 0,40 & $-0,14$ & 0,01 & $-0,04$ & 0,14 & $9,56 \mathrm{E}-03$ \\
CASELLA & 0,40 & $-0,08$ & 0,20 & $-0,15$ & 0,26 & $1,29 \mathrm{E}-02$ \\
\hline
\end{tabular}

layer; the wind speed here equals the undisturbed wind velocity. This layer separates the region characterized by strong airflow regimes above the collector $\left(U_{w}<U_{m}\right.$, red color) from the recirculating airflow zone inside the gauge $\left(U_{w}>U_{m}\right.$, blue color); this feature is corroborated by Nešpor [1998]. In the EML SBS500 case (panel $d$ ), the shear layer spans across the orifice and touches the downwind edge of the collector; this occurs to a lesser extent for the EML ARG100 gauge (panel c). This behaviour is partially explained by the stronger downdrafts occurring inside the EML SBS500 and ARG100 collectors (Figures 6 and 7) which pulls the shear layer downwards towards the downwind edge. Conversely, this does not occur for the shear layers of the OTT and the Casella airflows (panels $a$ and $b$, respectively) as they develop beyond the downwind edge of the collector and reach higher vertical levels than in the aerodynamic cases. In addition, the airflow vectors and the contours of the velocity magnitude for the aerodynamic gauges (panels c and d of Figure 9) show that stronger recirculation patterns occur inside the gauge collector when the shear layer spans 


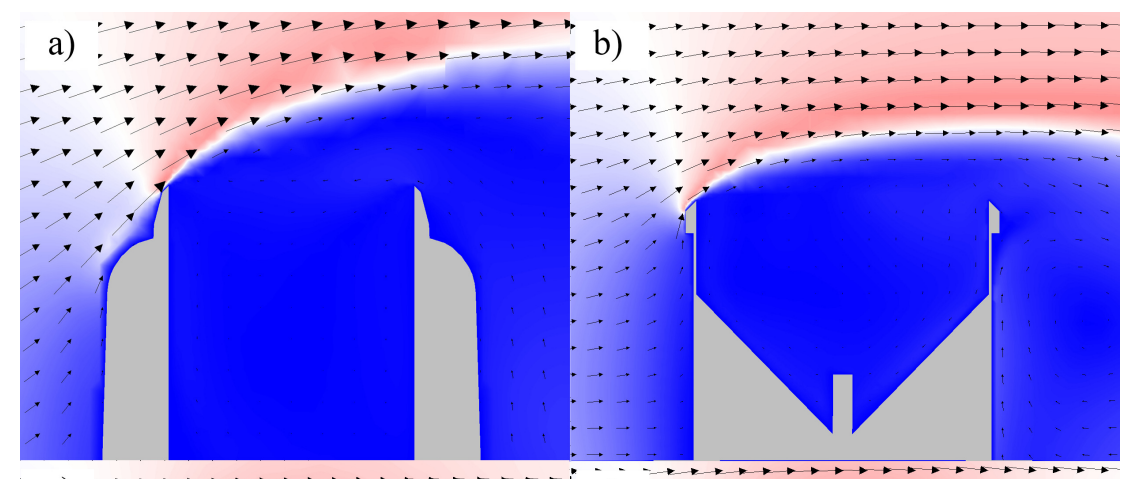

c) $\ldots \ldots \ldots \ldots \ldots \ldots \ldots \ldots \ldots \ldots \ldots \ldots \ldots \ldots \ldots$
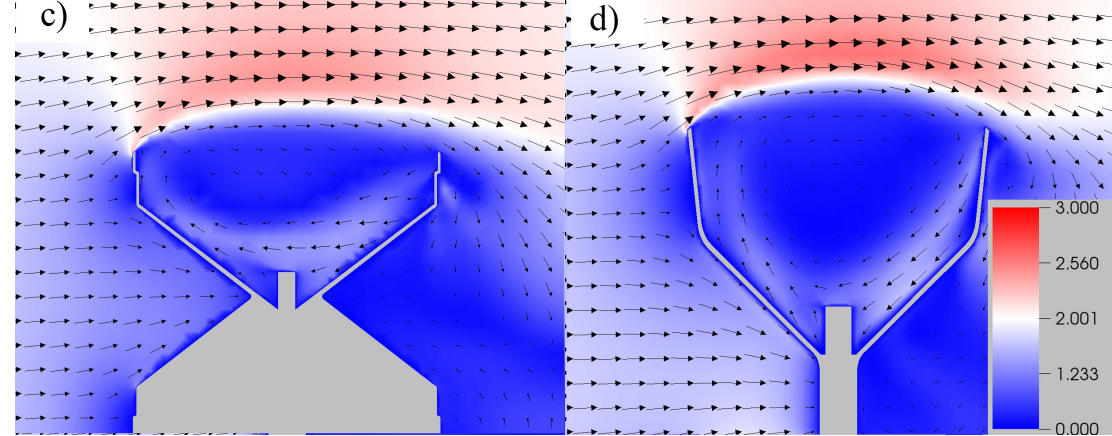

Figure 9. Color plots of the vertical stream wise section of the airflow magnitude of velocity $U_{m}\left(\mathrm{~ms}^{-1}\right)$ observed at the collector level of the OTT Pluvio ${ }^{2}$ (a), Casella (b), EML ARG100 (c) and EML SBS500 (d). The values have been computed by executing SST RANS $k-\omega$ simulations with a horizontal wind speed $U_{w}$ equal to $2 \mathrm{~ms}^{-1}$. The arrows represent the time-averaged airflow.

Table 6. Maximum values of the air velocity magnitude $\max \left(U / U_{w}\right)$, turbulent kinetic energy $\max \left(k / U_{w}^{2}\right)$ observed in the center of the collector $(x / D=0$ and $y / D=0)$ at level $z / D_{\max }$ for a wind speed $U_{w}=10$ $m s^{-1}$ evaluated by the RANS $k-\omega$ SST model

\begin{tabular}{r|cccc} 
& $\max \left(U / U_{w}\right)$ & $z / D_{\max (U)}$ & $\max \left(k / U_{w}^{2}\right)$ & $z / D_{\max (k)}$ \\
\hline ARG100 & 1,28 & 0,26 & $6,10 \mathrm{E}-03$ & 0,06 \\
SBS500 & 1,29 & 0,25 & $2,49 \mathrm{E}-03$ & 0,10 \\
OTT & 1,18 & 0,43 & $2,65 \mathrm{E}-02$ & 0,19 \\
CASELLA & 1,20 & 0,29 & $6,70 \mathrm{E}-03$ & 0,08
\end{tabular}

closer to the downwind edge, while the 'cylinder'-shaped Casella and the 'chimney-shaped' OTT models are characterized by much weaker recirculating airflows.

The vertical profiles of the horizontal component of the airflow velocity $\left(U_{x}\right)$ observed above the orifice level (see Figure 10) are characterized by a similar behaviour among the gauges characterized by an aerodynamic shape. By increasing the wind speed, the profiles maintain the same shape and rescale their values accordingly. Table 6 details the maximum value of the air velocity magnitude in non-dimensional terms and the associated vertical level expressed in collector diameter units $D$. The OTT profiles of $U_{x}$ reach their maximum values at a higher level $(z / D=0.43)$ compared to the $\operatorname{SBS500}(z / D=0.25), \operatorname{ARG100}(z / D=$ $0.26)$ and the Casella gauge $(z / D=0.30)$ as corroborated by Figure 9. 


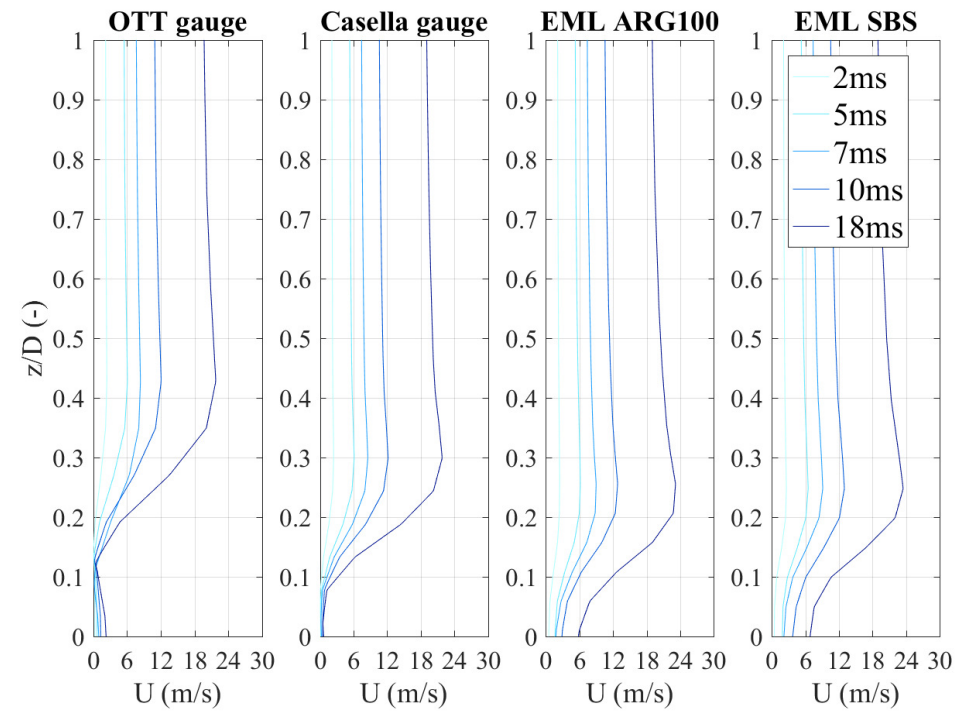

Figure 10. Vertical profiles of the horizontal component of the airflow velocity $U_{x}\left(m s^{-1}\right)$ observed in the center of the collector $(x / D=0$ and $y / D=0) ; z / D=0$ represents the orifice level. The values have been computed by executing SST RANS $k-\omega$ simulations at various wind speeds. 


\subsection{Turbulent kinetic energy}

The turbulent kinetic energy $k$ provides an indication of the level of turbulence generated by the rain gauge shape. Using real-world $k$ boundary conditions [Pollock et al., 2015] retains the wind speed characteristics that are enforced on the system in the field. These can be non-parameterised and scaled according to each input wind speed selected.
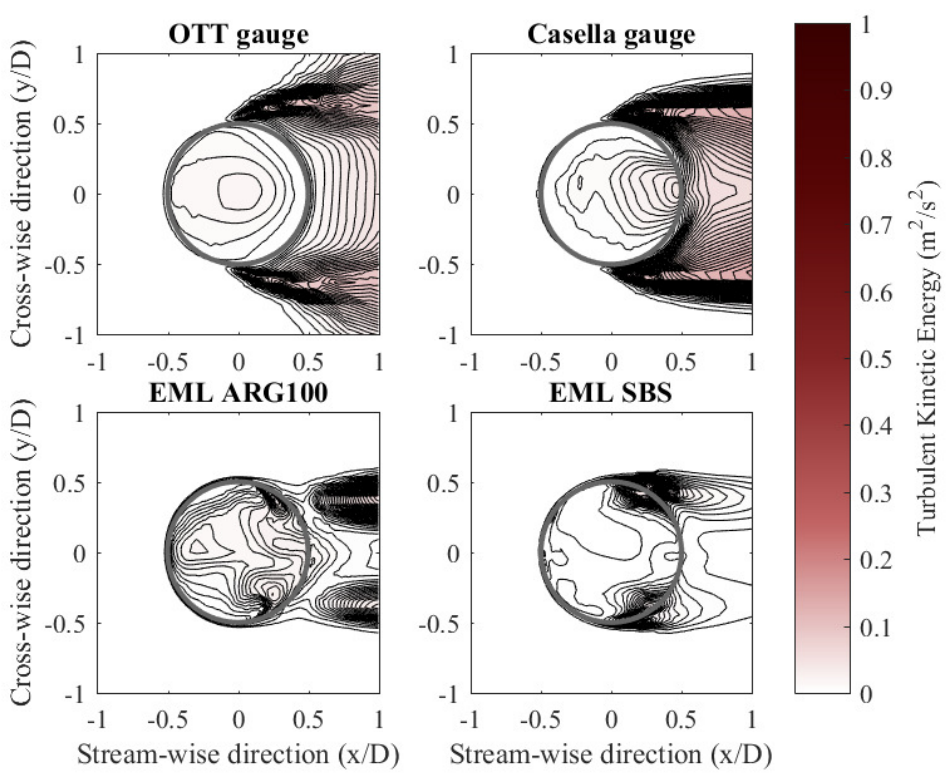

Figure 11. Horizontal contour plots of the airflow turbulent kinetic energy $k\left(\mathrm{~m}^{2} \mathrm{~s}^{-2}\right)$ observed at the gauge collector level. The values have been computed by executing SST RANS $k-\omega$ simulations with a horizontal wind speed $U_{w}$ equal to $2 \mathrm{~ms}^{-1}$. The spatial coordinates are normalized with the collector diameter.

The contour plots reported in Figures 11 and 12 focus on a horizontal plane located at the gauge collector level. At a wind speed equal to $2 \mathrm{~ms}^{-1}$ the aerodynamic gauges and the Casella are characterized by comparable levels of $k$, which are slightly lower than the turbulent kinetic energy figures observed in the OTT panel. By increasing the wind speed, the turbulence contours display the characteristics of non-linear growth. The lowest values of these are observed for the EML SBS500 gauge, which demonstrates better aerodynamic performance at the level of the collector. This result is also confirmed by the vertical $k$ contours plotted in Figure 13, computed with $U_{w}=10 \mathrm{~ms}^{-1}$. The OTT and the Casella gauges show significant turbulence inside the collector at the orifice level, which could have a direct impact on the precipitation trajectories. The non-dimensional $k$ values reported in Table 5 demonstrate such behaviour, with $k / U_{w}^{2}=0.011$ observed for the OTT gauge, $k / U_{w}^{2}=0.009$ for the Casella model while the ARG100 and SBS500 result in $k / U_{w}^{2}=0.007$ and $k / U_{w}^{2}=0.002$ respectively. It is also recognizable that the 'champagne glass' shape of the aerodynamic gauges creates a different turbulent structure in the wake (Figure 13). Furthermore, the airflow vectors in Figure 13 show that the recirculation region inside the gauge collector is stronger for the EML aerodynamic gauges and this occurs at all the tested wind regimes. Figure 14 depicts the vertical profiles of $k$ observed above the gauge collector which, in addition to Figure 13, confirms the superior aerodynamic behaviour of the SBS500 in reducing turbulence. Table 6 highlights that the OTT weighing gauge has a traditional 'chimney' shape that results in a turbulence level $\left(k / U_{w}^{2}=0.026\right.$ observed with $U_{w}=10 \mathrm{~ms}^{-1}$ ) which is one order of magnitude higher than the other gauges. In addition, the height of the high $k$ zone is smaller in the case of the ARG100 and SBS500 gauges (re- 

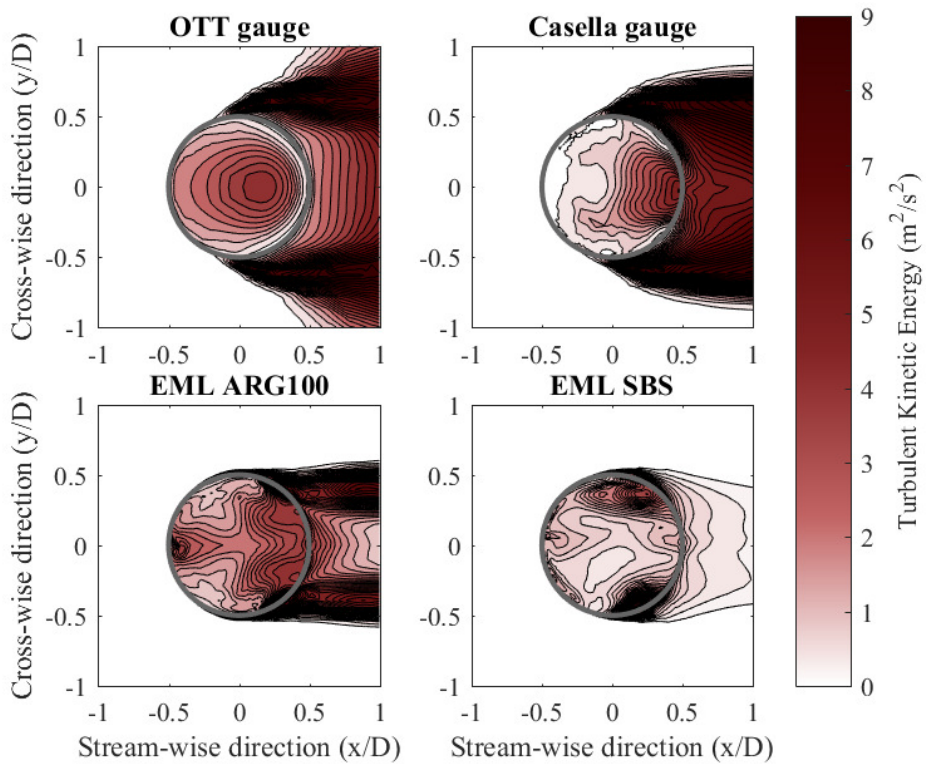

Figure 12. Horizontal contour plots of the airflow turbulent kinetic energy $k\left(\mathrm{~m}^{2} \mathrm{~s}^{-2}\right)$ observed at the gauge collector level. The values have been computed by executing SST RANS $k-\omega$ simulations with a horizontal wind speed $U_{w}$ equal to $18 \mathrm{~ms}^{-1}$. The spatial coordinates are normalized with the collector diameter.

spectively $z / D=0.06$ and $z / D=0.10$ against $z / D=0.19$ of the OTT). Indications are that this behaviour is likely to lead to an improved catch efficiency for the SBS500 when compared to the other gauges. 


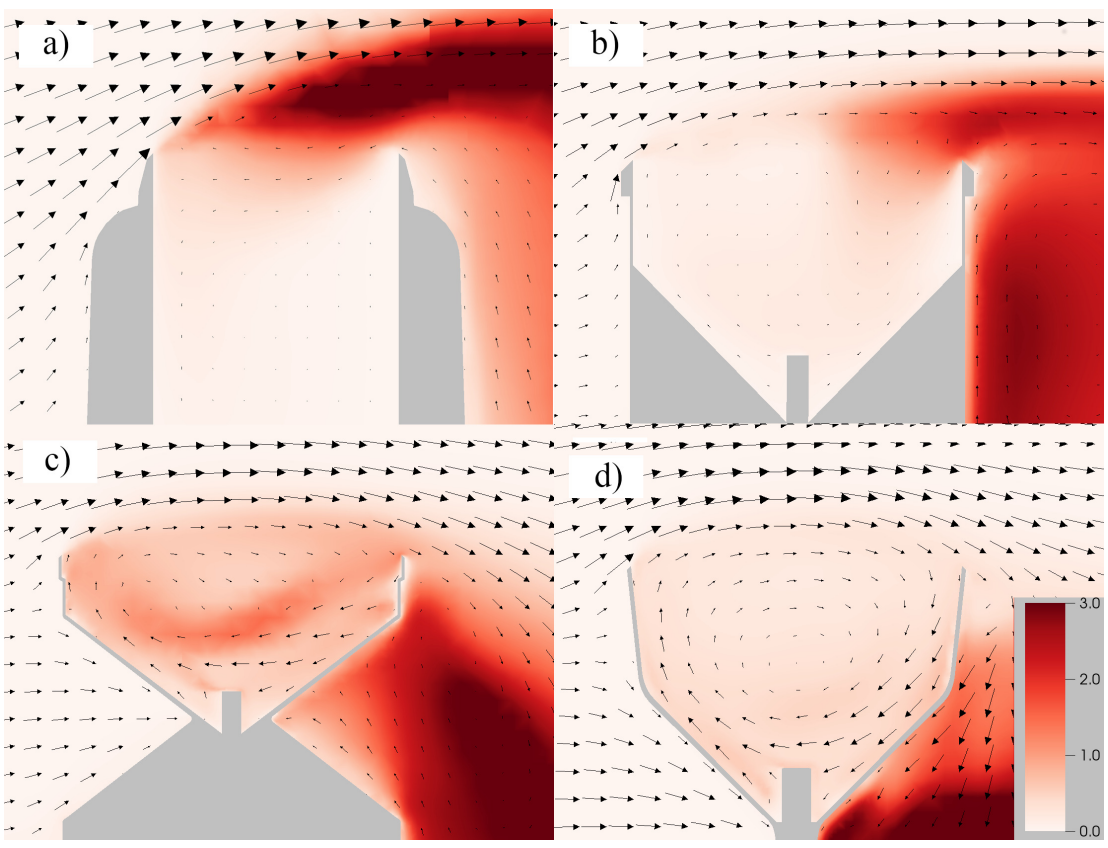

Figure 13. Color plots of the vertical stream wise section of the airflow turbulent kinetic energy $k\left(m^{2} s^{-2}\right)$ observed at the collector level of the OTT Pluvio ${ }^{2}$ (a), Casella (b), EML ARG100 (c) and EML SBS500 (d). The values have been computed by executing SST RANS $k-\omega$ simulations with a horizontal wind speed $U_{w}$ equal to $10 \mathrm{~ms}^{-1}$. The arrows represent the time-averaged airflow.

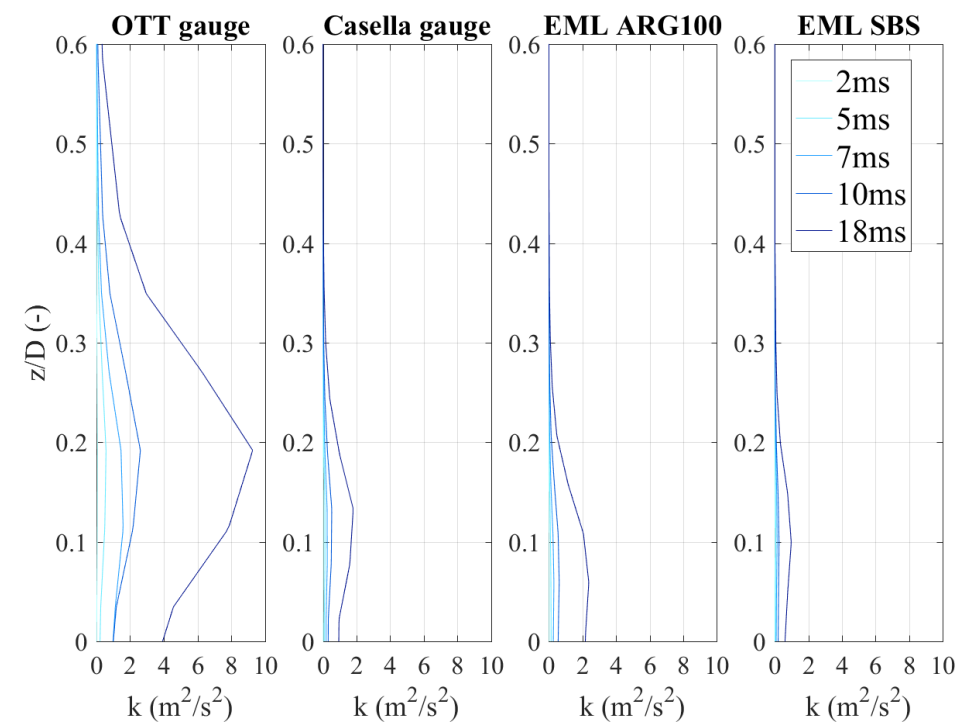

Figure 14. Vertical profiles of the airflow turbulent kinetic energy $k\left(m^{2} s^{-2}\right)$ observed in the center of the collector $(x / D=0$ and $y / D=0) ; z / D=0$ represents the orifice level. The values have been computed by executing SST RANS $k-\omega$ simulations at various wind speeds. 


\section{Discussion and Conclusions}

Although it has been known for more than 150 years that a conventional cylindrical rain gauge shape interferes with the flow of air, leading to undercatch, the problem has not received the recognition or attention it deserves. It is an 'a priori' assumption that, as the distortion to the airflow around a rain gauge and the turbulence above the gauge orifice increases, the catch efficiency of a rain gauge reduces and becomes less predictable and more heterogeneous. The results of the CFD simulations reported here provide 'a posteriori' confirmation of the above in the form of quantified evidence for conventional and aerodynamic rain gauge shapes. The findings of this study support the recommendation of Sieck et al. [2007] which states that until the rainfall catch of above-ground rain gauges can be quantified reliably, a variety of mitigation methods should be considered including using 'innovative gauge designs that are aerodynamically less intrusive to the environment'.

The main conclusions which can be drawn from the results are the following:

1. The CFD model results indicate that the outer shape of a rain gauge has a strong aerodynamic impact, when affected by wind, in terms of its potential ability to collect precipitation.

2. While previous experimental and analytical studies have suggested that aerodynamicallyshaped gauges should mitigate undercatch, the CFD simulations reported in this paper have provided strong evidence in support of this, and shown clearly the differentiation between conventional and aerodynamic gauge shapes.

3. The spatial distribution of the air velocity contours of Figures 6, 7 and 9 show clearly that the aerodynamic gauges have better airflow characteristics than the conventionallyshaped gauges.

4. Spatial plots of the turbulent kinetic energy $k$ in Figures 11-14 reinforce the previous conclusion by providing an understanding of the interaction between gauge shape and turbulence in the airflow around the gauges tested.

5. Recirculation patterns with strong downdrafts exist within the airflow plots for the aerodynamic gauges which are largely absent for conventional gauges. This is due to the shear layer intersecting with the downstream rim of the aerodynamic gauges, thus feeding the recirculation which has the potential to improve catch efficiency.

6. Numerical measures of aerodynamic performance have been quantified from the CFD simulations for both the airflow and the turbulent kinetic energy. The results, summarized in Tables 5 and 6, reinforce the observational evidence in the plots referred to in the above conclusions. In particular, the results regarding the turbulent kinetic energy field presented in Tables 5 and 6 for the SBS500 have the potential to be of striking significance. As Figures 13 and 14 demonstrate, the turbulent kinetic energy above its orifice is very low; even when forced with wind conditions of $18 \mathrm{~ms}$, the maximum value was less than $1 \mathrm{~m}^{2} \mathrm{~s}^{-2}$.

7. Using real-world airflow boundary conditions for a field site in the North East of England retains the wind speed characteristics that are enforced on the modeled system. Within this field of research this is a unique approach which, most significantly, provides the turbulent kinetic energy $k$ produced at the input boundary conditions. These can be non-parameterised and scaled according to each input wind speed selected. A high-resolution field campaign at this site is currently underway with the aim of further validating the CFD simulations, which are as such bespoke for this particular field research station.

8. Overall, the design of the 'champagne glass' SBS500 gauge provides the best aerodynamic performance among the gauges which were tested. The 'funnel'-shaped ARG100 gauge displays a similar effect, however it is not as strong as the SBS500. The 'cylinder' shaped Casella gauge has a reduced aerodynamic performance compared to the ARG100 and the SBS500. The shape of the 'chimney'- shaped Pluvio ${ }^{2}$ 
rain gauge indicates the worst aerodynamic performance when confronted by an airflow.

The low turbulent kinetic energy value for the EML SBS500 gauge could give rise to a more straightforward derivation of the rainfall undercatch, based on a theoretical relationship derived from the law of the flow field above the gauge orifice, and the wind speed measured at the gauge orifice. Wind speed is accelerated above any gauge which is mounted such as to present a blockage to the prevailing airflow. The 'consistency' of the accelerated wind speed however represents a significant advantage for the EML SBS500 when compared to the other gauges. This is a feature of the predictability of how the wind acts above the orifice of the SBS500, which has the potential to make applying a wind correction more straightforward and, importantly, justifiable from a physical perspective as opposed to a statistical model. A method of further investigating the turbulence would be to carry out time dependent Large Eddy Simulations (LES), but with significantly higher computational costs.

The expected impact of this research is to foster more accurate precipitation measurements by raising the awareness of the now greatly understated relevance of measurement accuracy in hydrological applications having a strong societal impact (floods, water resources, climate trends, etc.). We believe that a sound scientific basis is essential to demonstrate that biases in traditional rain gauge measurements are not negligible in current operational networks and may lead to large errors in the interpretation of precipitation patterns in both space and time, as exemplified by the study of Archer et al. [2007].

The interpretation of rainfall patterns, speculations about the nature of the rain field, scaling $v s$. non-scaling issues, rainfall event modelling and forecasting efforts, everyday engineering applications, etc., are indeed all based on the analysis of rainfall intensity measurements that are recorded at a much lower accuracy than the available technology would actually permit, particularly in upland/mountainous areas where higher windspeeds occur. Existing technology is not being used as effectively as it could and should be. This is either due to a lack of awareness of the issues discussed in this paper, or else due to an underestimation of their importance and significance. In either case it is hoped that the impact of this paper goes some way to raising awareness in both cases. 


\author{
Acronyms \\ WMO World Meteorological Organization \\ RANS Reynolds Averaged Navier Stokes \\ SST Shear Stress Tensor \\ LES Large Eddy Simulations
}

\title{
References
}

Active, W. (2017), Case studies: Environment agency builds new technology into rain monitoring network.

Archer, D. R., F. Leesch, and K. Harwood (2007), Learning from the extreme river tyne flood in january 2005, Water Environ. J., 21(2), 133-141.

Ariff, M., S. M. Salim, and S. Cheah (2009), Wall $y^{+}$strategy for dealing with wall-bounded turbulent flows, in Proceedings of the International MultiConference of Engineers and Computer Scientists, Hong Kong, vol II.

Bardina, J., P. Huang, and T. Coakley (1997), Turbulence modeling validation, testing, and development, Technical Memorandum 110446, NASA.

Benning, J., and D. Yang (2005), Adjustrment of daily precipitation data at Barrow and Nome Alaska for 1995-2001, Arct. Antarct. Alp Res., 37(3), 267-283.

Chubb, T., M. J. Manton, S. T. Siems, D. Peace, and S. P. Bilish (2015), Estimation of windinduced losses from a precipitation gauge network in the australian snowy mountains, $J$. Hydrometeor., 16, 2619-2638.

Colli, M. (2014), Assessing the accuracy of precipitation gauges: a CFD approach to model wind induced errors., Ph.D. thesis, University of Genova, Doctoral School in Science and Technology for Engineering.

Colli, M., R. Rasmussen, J. M. Thériault, L. Lanza, C. Baker, and J. Kochendorfer (2015), An improved trajectory model to evaluate the collection performance of snow gauges, $J$. Appl. Meteor. Climatol., 54(8), 1826-1836.

Colli, M., L. Lanza, R. Rasmussen, and J. M. Thériault (2016a), The collection efficiency of shielded and unshielded precipitation gauges, Part I: CFD airflow modelling, J. Hydrometeor., 17(1), 231-243.

Colli, M., L. Lanza, R. Rasmussen, and J. M. Thériault (2016b), The collection efficiency of shielded and unshielded precipitation gauges, Part II: modelling particle trajectories, $J$. Hydrometeor., 17(1), 245-255.

Constantinescu, S., W. Krajewski, C. Ozdemir, and T. Tokyay (2006), Simulation of flow around raingauges: Comparison of LES with RANS models, Adv. Water Resour., 30, 43 58.

EN (2002), Hydrometry. specification for a reference raingauge pit, Hydrometers, Gauges, Rainfall, Tre, eN 13798:2002 (revised 2010).

Folland, C. (1988), Numerical models of the raingauge exposure problem, field experiments and an improved collector design, Quart. J. Roy. Meteor. Soc., 114(484), 1485âĂŞ1516.

Goodison, B., P. Louie, and D. Yang (1998), WMO solid precipitation measurement intercomparison: final report, WMO Tech. Document 872, World Meteorological Organization, Geneva, Switzerland.

Grust, K., and D. Stewart (2012), UK trial of the OTT Pluvio, in BHS Eleventh National Symposium, Hydrology for a Changing World, Dundee, UK.

Heberden, W. (1769), Of the different quantities of rain which appear to fall, at different heights, over the same spot of ground, Philos. Trans., 59, 359-362.

Jasak, H. (1996), Error analysis and estimation for the finite volume method with applications to fluid flows, Ph.D. thesis, University of London, Imperial College of Science, Technology and Medicine, Department of Mechanical Engineering. 
Lanza, L., and L. Stagi (2009), High resolution performances of catching type rain gauges from the laboratory phase of the WMO Field Intercomparison of Rain Intensity Gauges, Atmos. Res., 94, 555-563.

Lanza, L., and E. Vuerich (2009), The WMO Field Intercomparison of Rain Intensity Gauges, Atmos. Res., 94, 534-543.

Launder, B., and D. Spalding (1974), The numerical computation of turbulent flows, Computer Methods in Applied Mechanics and Engineering, 3(2), 269-289.

Mekonnen, G. B., S. Matula, F. Doležal, and J. Fišák (2015), Adjustment to rainfall measurement undercatch with a tipping-bucket rain gauge using ground-level manual gauges, Meteor. Atmos. Phys., 127(3), 241-256,

Menter, F. (1993), Zonal two equation k- $\omega$ turbulence models for aerodynamic flows, AIAA 24th Fluid Dynamics Conference, 93-2906.

Nešpor, V. (1998), Estimation of the wind-induced error of the OTT 'Pluvio' precipitation gauges, department of Geography. Swiss Federal Institute of Technology ETHZ, Zurich, $44 \mathrm{pp}$.

Pan, X., D. Yang, Y. Li, A. Barr, W. Helgason, M. Hayash, P. Marsh, J. Pomeroy, and R. Janowicz (2016), Bias corrections of precipitation measurements across experimental sites in different ecoclimatic regions of western Canada., The Cryosphere, 10, 2347-2360.

Pollock, M., M. Colli, G. O’Donnell, A. Black, M. Stagnaro, M. Dutton, L. Lanza, P. Quinn, and E. O'Connell (2015), Evaluating wind-induced uncertainty on rainfall measurements by means of cfd modelling and field observations, in Rainfall in urban and natural systems, edited by 10th International Workshop on Precipitation in Urban Areas, Pontresina, Switzerland.

Sevruk, B. (1982), Methods of correction for systematic error in point precipitation measurement for operational use, WMO (Series), Secretariat of the World Meteorological Organization.

Sevruk, B., and W. Hamon (1984), International comparison of national precipitation gauges with a reference pit gauge, WMO-IOM 17, Tech. Document 38, World Meteorological Organization, Geneva, Switzerland.

Sevruk, B., J. A. Hertig, and R. Spiess (1991), The effect of a precipitation gauge orifice rim on the wind field deformation as investigated in a wind tunnel., Atmos. Environ., 25(7), 1173-1179.

Sieck, L. C., S. J. Burges, and M. Steiner (2007), Challenges in obtaining reliable measurements of point rainfall, Water Resour. Res., 43(1), n/a-n/a, w01420.

Strangeways, I. (2004), Improving precipitation measurement, Int. J. Climatol., 24, $1443-$ 1460.

Thériault, J., R. Rasmussen, K. Ikeda, and S. Landolt (2012), Dependence of snow gauge collection efficiency on snowflake characteristics, J. Appl. Meteor. Climatol., 51, 745-762.

Warnick, C. (1956), Influence of wind on precipitation measurements at high altitudes, Engineering Experiment Station Bullettin 10, University of Idaho.

Wilcox, D. C. (2006), Turbulence Modeling for CFD, 3rd ed., D C W Industries.

WMO (2012), Guide to Meteorological Instruments and Methods of Observation, 7th ed., Geneva, Switzerland, wMO-No. 8.

Wolff, M., K. Isaksen, A. Petersen-Øverleir, K. Ødemark, T. Reitan, and R. Bækkan (2014), Derivation of a new continuous adjustment function for correcting wind-induced loss of solid precipitation: results of a norwegian field study, Hydrol. Earth Syst. Sci., 9(11), 10,043-10,084.

Yang, D., B. E. Goodison, J. R. Metcalfe, P. Louie, G. Leavesley, D. Emerson, C. L. Hanson, V. S. Golubev, E. Elomaa, T. Gunther, T. Pangburn, E. Kang, and J. Milkovic (1999), Quantification of precipitation measurement discontinuity induced by wind shields on national gauges, Water Resour. Res., 35(2), 491-508. 